BULLETIN Bulletin hispanique

HISPANIQUE Université Michel de Montaigne Bordeaux

119-1 | 2017

Autorité et pouvoir dans le théâtre du Siècle d'Or

\title{
Poder y amor en las comedias mitológicas calderonianas
}

\section{Enrique Rull}

\section{(2) OpenEdition \\ 12 Journals}

\section{Edición electrónica}

URL: http://journals.openedition.org/bulletinhispanique/4914

DOI: 10.4000/bulletinhispanique.4914

ISBN: 979-10-300-0142-6

ISSN: 1775-3821

Editor

Presses universitaires de Bordeaux

Edición impresa

Fecha de publicación: 15 junio 2017

Paginación: 259-270

ISBN: $979-10-300-0141-9$

ISSN: 0007-4640

\section{Referencia electrónica}

Enrique Rull, «Poder y amor en las comedias mitológicas calderonianas », Bulletin hispanique [En línea], 119-1 | 2017, Publicado el 15 junio 2020, consultado el 10 septiembre 2020. URL : http:// journals.openedition.org/bulletinhispanique/4914; DOI : https://doi.org/10.4000/bulletinhispanique. 4914 


\title{
Poder y amor en las comedias mitológicas calderonianas ${ }^{1}$
}

\author{
ENRIQUE RULL \\ UNED
}

Il est démontré, dans cette étude, que l'opposition pouvoir/amour implique la corroboration d'un schéma moral qui s'applique à chacun des cas, tant en fonction des éléments du mythe concerné qu'à travers sa réalisation dramatique. Dans tous les cas, c'est l'amour qui l'emporte sur le pouvoir, soit comme couronnement (érotique) soit comme renoncement (agapé)

Mots-clés: Calderón, amour, pouvoir, mythologie.

En este estudio creemos haber mostrado cómo la oposición poder/amor entrańa la corroboración de un esquema moral en donde en cada caso se aplica según las circunstancias del mito en cuestión, pero también a través de su realización dramática, superponiéndose en ambos casos como principio prevalente el amor sobre el poder, ya sea como coronación positiva (erótica) o de renuncia (ágape).

Palabras clave: Calderón, amor, poder, mitología.

In this study we have shown how the opposition between power and love involves the corroboration of a moral standard. This scheme is applied in each case according to the circumstances of the myth in question. Throughout its realization the dramatic overlap in both cases works as a principle where love's prevalence over power appears either as positive Coronation (erotic) or waiver (agape).

Keywords: Calderón, love, power, mythology.

1. Este artículo se inserta en el marco del proyecto de investigación FFI2014-52007-P, «Autoridad y poder en el teatro del Siglo de Oro. Estrategias, géneros, imágenes en la primera globalización», financiado por el Ministerio de Economía y Competitividad del Gobierno de España. 
G ${ }^{1}$ poder y el amor están íntimamente unidos, ya sea como unión de Eambos, como oposición o como fagocitación de uno por otro. En el teatro especialmente, como técnica de tensión de opuestos, es verdadera clave de infinitas historias. Nada tiene de extraño por tanto que en el del Siglo de Oro se practicase esta oposición con cierta frecuencia disfrazada en multitud de temas, esencialmente trágicos, pero también en la comedia y otros géneros. En el mitológico no podía estar ausente, como veremos en el siguiente recorrido a través del drama calderoniano de este asunto. La referencia a los mitos parte de la convicción de que, como ocurría en la Antigüedad, este género posee un «alto valor paradigmático por su conocimiento generalizado» suministrando «a los autores trágicos modelos, narraciones y situaciones de los más variados actos violentos y criminales ligados a las pasiones humanas (los celos, la venganza, la ira, la locura), al abuso del poder de tiranos y déspotas o, simplemente, a las guerras» (Caballero López 2013: 41-55), como señala J. A. Caballero López refiriéndose al antiguo teatro griego, pero cuyas palabras podrían muy bien traerse a colación y aplicar al teatro aurisecular, salvando las distancias, especialmente al de Calderón. El dramaturgo dedicó, sobre todo en sus últimos años, no menos de dieciocho dramas a este género. Algunos de ellos, que analizaremos aquí, presentan componentes esenciales de conflicto poder-amor.

La comedia El mayor encanto amor es uno de los primeros intentos en este género, que data ya de $1635^{2}$. Algunos datos que muestran el sentido dramático de la oposición amor-poder, en relación con la misma estructura de la obra, se manifiestan en la utilización de los recursos escénicos y de la música, como ya analizamos en otra ocasión (Rull 2004: 31). Destacamos entonces el valor de los coros contrapuestos, uno relativo a la toma de armas de Ulises, el otro a los cantos de sirena de amor para que permanezca junto a Circe: «La oposición de los Coros crea un ámbito de contrastes dinámicos (por la índole misma de su esencia musical), de tensiones dramáticas e incluso de espectacularidad estereofónica, dado que ambos no sólo están contrapuestos en su esencia, sino dispuestos de forma que uno provenga del mar donde están los compañeros de Ulises y el otro de la tierra donde permanece Circe, creando un frente musical de adecuado contraste significativo» ${ }^{3}$. No sería la primera vez que Calderón utilizaría el escenario para crear oposiciones dramáticas y a la vez escénicas en el teatro mitológico. Recordemos cómo en la comedia Los tres mayores prodigios llega a utilizar tres teatros para dramatizar las tres historias de que se compone la comedia, hilvanadas por la de Hércules, pero en El mayor encanto, amor lo que importa destacar es cómo toda la comedia juega con dos valores: los asignados al poder y al amor respectivamente, y el interés estriba en cuál de ellos será el que se alzará triunfante a la postre. Aquí el amor se concibe bajo especie de tentación con todos los encantos que la maga Circe está dispuesta a

2. Ofrecemos los datos esenciales de la misma (representación, escenografía, decorados, argumento, fuentes y análisis) en nuestra edición y estudio de Celos aun del aire matan, 2004, pp. 25-32.

3. Ibid. 
desplegar, algunos no exentos de maldad, como cuando hace arder el mar para cortar la retirada a su amante. En realidad lo que se traduce de la historia es la lucha de dos poderes enfrentados: el amor con sus encantos, frente al poder de decisión personal o libre albedrío, que es en el fondo el tema moral que infunde Calderón en la obra, que así deja de ser sólo un espectáculo de tramoyas y música para alcanzar una finalidad superior. Por supuesto que será Ulises el que venza, y el amor en este caso quedará relegado a la libertad de elección personal, que se erige en bien supremo, lo que no quiere decir que la libertad sea un bien preferible al amor, sino que éste ha de ser libre para ser verdadero amor, por tanto lo que preconiza la comedia, y por ello mismo el propio autor, no es tanto un enfrentamiento de poder/amor como una armonización libre, pues en el fondo lo que Circe quiere lograr no es amor sino puro deseo de posesión, es decir, de preeminencia de su poder.

En la originalísima comedia La fiera, el rayo y la piedra, la antítesis principal entre poder y amor se produce realmente entre dos personajes divinos, Eros y su hermano Anteros, quienes luchan por hacer prevalecer una concepción distinta cada uno del amor. El primero, Cupido, representa el «amor absoluto", mientras que su hermano Anteros significa el «amor correspondido». Cuando Cupido quiere matar a su hermano, este huye a la esfera superior de Diana, mientras que aquel le dice que le perseguirá hasta darle muerte como "fiera, rayo y piedra», seres en cuya composición participa él mismo. Pero antes, Calderón opone otro dúo de personajes como Argante y Anajarte, a quien aquel mantiene prisionera en su alcázar, y a la vez lo combina con el conocido de Ifis y la propia Anajarte, haciéndose eco, por una parte, de la famosa y trágica leyenda de esta última, contada por Ovidio (Ovide 1962: 699-770), a la que el poeta latino convertía en piedra por su dureza para con su amante Ifis, a la vez que la mezcla con personajes novelescos como Argante, que con este nombre será igualmente persona también de la comedia Hado y divisa de Leónido y Marfisa (la última que escribiría Calderón), por cierto en una circunstancia muy similar a la del personaje de La fiera, porque mantiene prisionera, como aquí a Anajarte, a Marfisa para evitar un fatal presagio (todos evidentes reminiscencias del núcleo Basilio-Segismundo). Ifis y Anajarte constituyen, por tanto, una pareja amorosa de la obra, en este caso desafortunada por la dureza de ella para con quien la ama. La otra pareja es la de Pigmaleón y la estatua creada por él mismo de la que se enamora, y a quien Venus dará vida. Es el contrapunto de la historia de Anajarte, pues como observa Aurora Egido la historia de Anajarte trata de una «fábula simétrica, pero invertida, pues sus desdenes hacia Ifis acabaría convirtiéndose de mujer en estatua de mármol, como justo castigo por su pertinacia en la dureza» (Calderón de la Barca 1980: 55), y aquí sucede lo contrario, pues la dedicación amorosa, aunque desviada, tiene su compensación a los ojos de los dioses. La tercera historia es la de Céfiro con la salvaje Irífile, invención seguramente calderoniana, que nos retrotrae a la historia de Segismundo, pues Irífile aparece en una oscura cueva ignorante de su origen, ya que al nacer fue cambiada en la cuna con Anajarte, quien 
reina sobre Trinacria inmerecidamente, pues la reina verdadera corresponde a Irífile, quien al final recobrará su reino junto con el amor de Céfiro. Tres historias amorosas, pues, mediatizadas por los dioses, quienes aquí ejercen el verdadero poder sobre sus destinos, como ocurría en el mundo clásico. La clave, sin embargo, reside en este caso en dos dioses opuestos que manifiestan su poder sobre los humanos con acciones sobre sus vasallos netamente diferentes. Cupido o Eros, mediante su influencia sobre ellos en la sensualidad y en el amor desnortado, sin sentimiento y sin constancia, frente a Anteros, quien decide ejercer la influencia sobre los humanos con el amor correspondido y armónico. Es el que Calderón, valiéndose de la alegoría tamizada por el cristianismo, defenderá como idóneo, posiblemente con fundamento en la oposición entre Eros y Ágape, es decir, basándose en la idea del amor «creador», como ha visto muy bien Anders Nygren (1944 : 77). Las correspondencias entre el mundo clásico y el cristianismo estaban en la base de la cultura de entonces y acudir a esos paralelismos era casi instintivo. Pero no es imprescindible establecer esa comunicación de manera explícita, pues el teatro de la época ya había instituido de manera palmaria un mundo de referencias de la mitología con la sensibilidad moderna. En este caso, la materia circunstancial de los tres amores con desigual fortuna dependía de la concepción amorosa arraigada en la conciencia del deber y de la justicia, pues el poder que procede de los dioses, como vemos, se ejerce de manera ejemplar como justicia poética inapelable. Así, Irífile recibe lo que en justicia le corresponde, Anajarte es castigada por su dureza de sentimientos y Pigmaleón recibe el premio a su constancia y a su «amor eterno». Ya no estamos en la tragedia clásica determinista, sino en el reparador mundo de la justicia, que se ejerce en este caso desde el arte pero con un sustrato moral más moderno y propio de la cultura cristiana más acorde con el Ágape que con Eros. El poder, en este caso, es más que un poder de los dioses, ciego, arbitrario e injusto, un poder «divino» reparador, ejercido con un sentido arraigado de lo que debe ser la justicia distributiva.

Una transposición del tema del poder desde el ámbito mitológico con claras repercusiones en el mundo moderno lo tenemos en el mito de Faetón ${ }^{4}$. Calderón en El hijo del Sol, Faetón, vislumbró las posibilidades de acercamiento a un asunto de creciente actualidad como es el enfrentamiento generacional padre-hijo (Erídano, nombre de ambos) y el fraterno (Épafo-Peleo / ErídanoFaetón) y las repercusiones desde el lado del amor y la piedad, el derecho y la justicia, y la moral y la filosofía, entroncando también el ejemplo mitológico con la teología. Esta comedia es sumamente interesante para comprobar la transposición de los temas mitológicos a las ideas modernas con un sustrato basado en el poder y el amor. Efectivamente, Faetón, que a lo largo de la comedia se nombra como Erídano, está en continua competencia con su hermano Épafo. Ambos aman a la hermosa Tetis, pero mientras que Erídano

4. Ovide, op. cit., vv. 1-330. Sobre el mito de Faetón, su trayectoria en los Siglos de Oro y su supuesta modernidad puede verse el libro de A. Gallego Morell, 1961. Completado en un aspecto parcial por el trabajo de J. M. Rozas, 1963. 
salva a la dama de una fiera, su acción es atribuida a su hermano Épafo-Peleo. Cuando Erídano-Faetón decide ir en busca de la fiera descubre que es una mujer (en realidad es su propia madre, Climene), y que por ello mismo él es hijo de Apolo (el Sol), a quien pide como prueba que le deje conducir el carro del Sol durante un día. Apolo accede, y Faetón lo conduce contemplando desde lejos cómo Épafo (Peleo) roba a su amada Tetis a la que lleva a una cueva. Al observar con estupor esta escena, desvía el curso del carro, aproximándose peligrosamente a la tierra y quemando una parte importante de ella. Júpiter le castiga fulminándole con un rayo.

Toda la comedia es una fábula de cómo el poder y el amor se interrelacionan. En este caso, bajo unos condicionantes morales. La visión del poder nunca mejor que en este caso está representado como signo de verticalidad 5 . La axiología es un camino en el que, como dice Bachelard, «No se puede prescindir del eje vertical para expresar los valores morales» (Bachelard 1958: 21). El mito de Faetón, como el mito de Ícaro, representa en el mundo mitológico el paradigma necesario de esta ascensión soberbia que acaba en castigo y tragedia, pero en la obra calderoniana Faetón no es sólo soberbia de ambición, es ansia de poder reparador. La simbología de alcanzar el cielo, cumbre del máximo poder, se ejerce por medio de la mitología, como desagravio de un complejo de inferioridad con respecto a un hermano, taimado y traidor (ya que no ha sido capaz de desmentir el engaño en el que se ve envuelto, atribuyéndose el mérito que no le corresponde), lo que determina que Faetón decida reivindicar su valor y estirpe, pero el desencadenante de la tragedia radica no sólo en la soberbia de pretender alcanzar la cúspide del cielo, sino en el descubrimiento de que además se le va a arrebatar su amor. Decíamos que la comedia posee características que la entroncan con campos de la moral, el derecho, la filosofía e incluso la teología. A través del concepto del poder se articulan todos estos mundos. Decía Valbuena Briones que "Calderón al tratar el tema asigna a la figura de Faetón el atributo de la soberbia» (Valbuena Briones: 167). En el mito siempre se vio esa ambición insana, pero a la vez en el Siglo de Oro se pudo trasponer la idea a las vivencias contemporáneas, por ejemplo de alcanzar la pureza de sangre los sospechosos de contaminación de judaísmo, como vio Rozas (Rozas 1963: 81-92) o incluso los que deseaban alcanzar un estatus superior. El mito sirve para cada situación social o individual. Calderón, que aboga por problemas más existenciales y esenciales, se aparta de referencias concretas de época para indagar en el espíritu de rebeldía y ruptura con el orden. Así se muestra en las palabras del propio Faetón cuando avizora la traición de Épafo con Tetis:

\footnotetext{
Faetón ¿Quién creerá que en tanto asombro yo abrase al mundo y a mí? Mas, qué mucho si a mis ojos a Tetis, ¡ay, infelice!,
}

5. Para los conceptos axiológicos de la perspectiva vertical véase el estudio de Bachelard, 1958. 


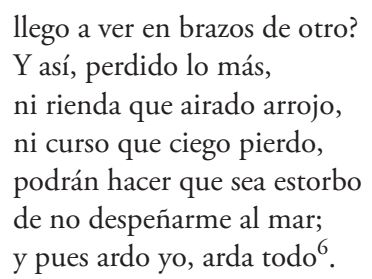

El poder nace de la reivindicación, y aunque la lección moral aparentemente es "cuán peligroso es desvanecerse» ${ }^{7}$, la pintura es la de un joven traumatizado por un destino adverso y una injusta traición amorosa, y su desesperada rebelión.

En la obra Celos aun del aire matan tenemos la antítesis de esta solución trágica ${ }^{8}$. Al tratar el mito de Céfalo y Procris, Calderón parte de una situación similar a la del mito de Apolo y Climene, en la que Pocris (así lo escribe siempre el dramaturgo) aparece asociada a Aura, ambas ninfas del templo de Diana, solo que Pocris la ha hecho prisionera por haberse enamorado de un hombre (Eróstrato) traicionando así su casta dedicación a la diosa. Esta oposición se verá contrarrestada por la intervención de Céfalo, quien, apiadado de Aura, la libera de sus ataduras a un árbol (mediante la intrusión divina de Venus, quien hace volar el árbol en el que Aura se halla atada). Pocris trata de enarbolar un venablo contra Céfalo pero se hiere con el hierro y descubre que acaba de herirse de amor también. La obra se complica con la intervención del pastor Eróstrato, quien incendia el tempo de Diana. La diosa entonces envía a las Furias a que se venguen de las ninfas. Céfalo, yendo de caza, es espiado por Procris, quien celosa le ha seguido. Cuando el pastor llama a «l'aura» (el viento suave y refrescante), Pocris cree que se refiere a otra dama (Laura) y, agitándose entre las matas, llama la atención de Céfalo, quien dispara la ballesta, pensando que es una pieza de caza e hiriendo gravemente a Pocris. En esencia Calderón sigue el relato de Ovidio, salvo en la historia de Aura y Eróstrato, y en la introducción de personajes rústicos, que tienen un gran papel, al menos en lo que se refiere a su función musical (ya que la obra es una extensa ópera española, escrita para ser cantada íntegramente) ${ }^{9}$. A nadie puede extrañar la inserción de elementos jocosos en la comedia mitológica, como también el carácter popular de algunas de estas obras, como ya estudió el profesor Gutiérrez Carbajo al referirse precisamente a Apolo y Climene $^{10}$.

Decíamos que esta obra era la antítesis de Apolo y Climene, e incluso de El hijo del Sol, Faetón, y lo es por la función que desarrolla precisamente el tema del poder referido al amor. Si en estas obras el poder de los dioses

6. Calderón, El hijo del Sol, Faetón, ed. 1959, p. 1951, a.

7. Ibid., p. 1951, b.

8. Para un estudio de esta obra puede verse nuestra edición de Celos aun del aire matan, 2004.

9. Para todos los pormenores de esta ópera, tanto literarios como musicales y referentes a la representación que se hizo en el año 2000 en el Teatro Real de Madrid, véase nuestra edición mencionada de 2004.

10. Véase F. Gutiérrez Carbajo, 2002. 
determinaba un final no convencional, no permitiendo a los amantes satisfacer su bienaventuranza con un destino feliz en la primera, o arrastrando al protagonista a un final tremendamente trágico, en la segunda, en Celos aun del aire matan sí se cumple ese final, contraviniendo, no obstante, la tradición de la fábula. Aventuro la posibilidad de que el autor haya elegido esta solución al tener entre sus manos un argumento en versión musical, o quizá simplemente ese final tan idealista haya pesado en el autor a la hora de considerar el enfrentamiento de dos diosas (Diana y Venus), verdadera oposición de poderes que determina en esencia la particularidad de su obra. Sabido es que Calderón, si ha de elegir entre la diosa casta y la, por antonomasia, del amor, elige siempre a la segunda. El final, aunque aparentemente acabe con la muerte de Pocris, en realidad, se altera con un salto que se aparta de las fuentes más frecuentes ${ }^{11}$, y Calderón decide preferir la sublimación de los amores con una ascensión a los cielos. Curiosamente no sólo de Céfalo y Pocris, sino también de Aura ${ }^{12}$. Así, el autor manifiesta que, entre el poder y el amor, debe prevalecer este último, siguiendo siempre el lema virgiliano "Omnia vincit amor», lo que no obsta para que en distintas ocasiones, cuando lo demanda la originalidad de su propio planteamiento dramático, pueda elegir otras soluciones menos sublimadoras y sí más trágicas alterando las fábulas a su conveniencia teatral.

Un drama en conexión con el mito de Faetón, al que hemos hecho frecuente alusión, es el de Apolo y Climene, en cierto modo precedente de aquel ${ }^{13}$. Por supuesto que Calderón se inspira esencialmente en Ovidio ${ }^{14}$, pero, como casi siempre, añadiendo ingredientes de su invención o combinándolos con otros. En la historia calderoniana de Apolo y Climene $^{15}$ vamos a encontrar una fábula amorosa en el fondo muy humana y, curiosamente, muy paralela a la comedia El galán fantasma, salvo en su tono y su desenlace. Pero además es una historia concebida desde una trascendencia no tanto proveniente del tema mitológico como de la perspectiva de un fatum más secular con el que está orientada su dirección y su desenlace. Es una obra complicada en cuanto a las situaciones, la abundancia de personajes y los lances, pero no mucho más que las comedias de enredo, como la que acabamos de mencionar. Sin embargo, como decimos, donde se marcan más las diferencias es en la complejidad de sus significaciones, de sus posibles orientaciones. Si la fábula es una historia

11. El profesor García Gual llamaba a este desenlace «hábil pirueta final», en donde no se le ocultaba que estaba realizada para destacar el triunfo del amor (Libreto 2000: 119). No obstante, como existen otros testimonios sobre un final similar en versiones del mito de países extranjeros, hay que pensar que Calderón debió de beber en una fuente común no conocida por nosotros.

12. Para más datos sobre este final, véase nuestro estudio y edición mencionados de 2004, pp. 93 y ss.

13. Sobre el tema y función de Apolo en el teatro calderoniano escribió el profesor Á. Valbuena Briones un estudio interesante titulado «El tema de Apolo en tres <comedias> de Calderón», 1981.

14. Ovide, op. cit., vv. 1-330 (junto con el mito de Faetón).

15. Tenemos en cuanta aquí algunas opiniones y datos que ya incluimos en nuestro estudio «El camino de la mina vehículo de emociones en Calderón», 2002. 
cerrada por provenir de un tema mitológico dado, su realización se abre a múltiples incógnitas sobre la orientación de la vida y de sus pasiones, sin que se nos cierre su explicación a un único valor y sentido. Pero en ella, como veremos, se ha realizado una síntesis de drama, comedia «de fábrica» y fábula mitológica. Es la historia de una ninfa virgen, Climene, dedicada al culto de Diana, pero no voluntariamente, sino que, cual Segismundo en La vida es sueño, ha sido encerrada por su padre, Admeto, quien, siguiendo el adverso horóscopo del mago Fitón, que la hacía madre de Faetón (causa de la desgracia del mundo al abrasar parte de éste con la errada conducción del carro del Sol) para evitar que pueda tener descendencia, decide hacerla sacerdotisa de la casta Diana y guardarla en una gruta entre muros y vigilantes, de forma que no pueda salir de allí y nadie la pueda ver. Por otra parte, esta historia guardará relación con la del dios Apolo, quien por recibir más sacrificios que el propio Júpiter en el templo que le estaba dedicado, fue objeto de las iras del celoso dios, quien le arrebató los poderes divinos y le envió a la tierra, donde conoció a Climene, la sacerdotisa de Diana.

Céfiro y Sátiro confiesan a su vez cómo vieron a un hombre salir de una mina y, de paso, mencionan a Climene. Ante lo cual Admeto, después de intentar herir a su hija, decide volverla a la prisión. Pero Apolo se la lleva lanzándose al Erídano. Apolo, en la tercera jornada, lleva en sus brazos a Climene, y, ante la duda de si dejarla o no para salvarse de la persecución de Admeto, aparece el mago del horóscopo fatal, Fitón, quien se encarga de su salvamento guardándola en un peñasco. A la llegada de Admeto, Fitón le deja creer que los fugitivos han muerto ahogados, pero Clicie, una de las ninfas del templo de Diana, no se deja engañar pues sabe que Apolo no puede morir. Se convierte el peñasco en un palacio, en donde aparece Climene en un trono, quien al despertar de su desmayo se muestra sorprendida de ver a Apolo y comprender que es más que un hombre:

$\begin{aligned} \text { Climene } & \text { Y si eres deidad que pudo } \\ & \text { el Erídano romper, } \\ & \text { y excelso alcázar hacer } \\ & \text { de un tosco peñasco, dudo } \\ & \text { cómo eres deidad que engañas, } \\ & \text { a Flora minas fingiendo, } \\ & \text { y a mí ilustrando montañas. }{ }^{16}\end{aligned}$

Apolo decide contar toda su historia anterior a la caída en la mina que le condujo hasta la ninfa:

$\begin{array}{ll}\text { Apolo } & \text { Pues entre la tempestad } \\ \text { que de sí me arroja, hube } \\ \text { de caer (imaginando } \\ \text { que aun los montes no me sufren) } \\ \text { sin saber dónde, en la sima } \\ \text { que a tus jardines conduce } \\ \text { ajeno amor. ¿Quién creerá }\end{array}$

16. Calderón, op. cit. p. 1899, b y 1900, a. 
que equivocando arcaduces, de minas que fueron de agua, minas de fuego resulten ${ }^{17}$

Entonces anuncia Fitón las bodas de Apolo y Climene. Perdonan los dioses a Apolo, pero no a Climene por haber roto el voto. Apolo no acepta, pues prefiere el amor de Climene antes que el perdón de los dioses. Mientras tanto, ante la llegada inminente de Admeto y el intento de Apolo de ausentarse para desenojar a los dioses, Fitón trata de ocultar a Climene. Admeto inquiere a Fitón por la identidad del amante de su hija; Clicie trata de explicárselo, pero al hacerlo enmudece, y lo mismo le pasa a Céfiro y a Flora. La primera se convierte en flor, Céfiro en viento y los demás desaparecen. Fitón reconoce que los hados se han salido "con sus influjos severos", que es reconocer a Admeto que se han cumplido los crueles hados. En el drama El hijo del sol, Faetón, que ya se anuncia aquí, vimos escénicamente representada la realidad de ese cumplimiento.

En el fondo esta historia de amor es la lucha de poderes entre Apolo y Diana, apoyada esta última por Júpiter. Y también la represión que representan Admeto y el mago Fitón con sus designios que imposibilitan a Climene realizarse como mujer que ama. Y si avanzamos un tanto veremos que es también la lucha entre el amor como pulsión anhelada y la castidad como norma. En este sentido, es importante tener en cuenta el «sensualismo" de la comedia que ha sido discutido, entre otros, por Parker (negándolo) y Hernández Araico (afirmándolo) ${ }^{18}$.

Para Climene la mina que le condujo a Apolo es una obra de amor («amor ingeniero»). Y como tal es un verdadero camino de liberación, principalmente de la prisión injusta a que le ha conducido su cruel padre de la mano del hado fatal. Hay en Calderón un verdadero camino de libertad en la elección de la acción de amar (más que del amor, propiamente dicho), aunque ese camino sea duro y suponga pagar una cuota muy dura en responsabilidad. Aun así, el que los personajes pongan a prueba su propia seguridad nos muestra que para el dramaturgo esta pasión posee una fuerza de transformación total, y por tanto una reivindicación de la persona, en tanto que sujeto amante y capaz de amar, frente a oposiciones y dificultades.

En cualquier caso, el final, contra lo acostumbrado, no acaba bien, cosa que ya Calderón se cuida mucho de advertírnoslo. Posiblemente haya pesado en el dramaturgo la idea de no repetir el final aparentemente feliz de su obra Celos aun del aire matan, anterior (data de 1660), ya que esta otra parece escrita un año después y no parecería oportuno reiterar la misma fórmula. Sea como fuere, en esta ocasión, el poder de los dioses prevalece y el horóscopo se cumple. ¿Puede argüirse que existe una ambivalencia entre las soluciones que ofrece Calderón en su teatro acerca de que en unas ocasiones prevalece el

17. Ibid., p. 1902, a.

18. Véanse los estudios al respecto de S. Hernández Araico, 1987 y 2002. 
amor y en otras el poder, y que por lo tanto no existe una norma ética positiva sino un final acomodaticio? Creo que no. No es que el amor ceda al poder, porque incluso en las escenas últimas de Apolo y Climene se realiza este amor, se escenifica y se ensalza. Cuando Apolo es instado por Mercurio e Iris para que vuelva al solio de cielo y abandone a la ninfa, a la que los dioses no perdonan que haya roto el voto del templo, el dios solar decide no aceptarlo, y sólo lo hará cuando sea la propia Climene la que renuncie y le ruegue que vaya, con estas palabras:

$\begin{array}{ll}\text { Climene } & \text { Primero } \\ \text { que te resuelvas, escucha } \\ \text { que te estimo como a dueño, } \\ \text { que te adoro como amante, } \\ \text { que como a esposo te quiero. } \\ \text { Amor lo sabe, y Amor } \\ \text { sabe también que este ruego, } \\ \text { bien a pesar del carińo, } \\ \text { le dicta el carińo mesmo. } \\ \text { Menos importa que yo } \\ \text { muera de mis sentimientos } \\ \text { que no, Apolo, que tú vivas } \\ \text { desterrado de tu centro. } \\ \text { En fe de que tú, gozoso, } \\ \text { ilustres campos de cielos, } \\ \text { páramos de montes yo } \\ \text { alegre viviré, viendo } \\ \text { al amanecer tus rayos }{ }^{19}\end{array}$

Así, Apolo accederá, dejándola guardada y oculta por Fitón, anunciando el dramaturgo una segunda parte de la comedia, que será la de El hijo del Sol, Faetón, del que ya sabemos su final trágico. Pudiera decirse que esta es una forma de escamotear un final no feliz, pero tampoco desgraciado, dando largas en esta obra a un desenlace en otra, o quizá tratando de establecer una serie de equidistancias o soluciones salomónicas, no comprometiéndose, como idea o sistema, en decidir entre amor y poder; pero esto es solo aparente, pues la imagen que prende en el espectador es la de un amor positivo realizado, y amplificado incluso, por una renuncia amorosa en la que se introduce el aspecto, señalado antes, de glorificación del sacrificio, como puede verse en el texto transcrito, es decir un amor más próximo al Ágape que a lo puramente sensual y erótico (Eros), aunque éste tenga un papel esencial en la obra. En cualquier caso, el triunfo del amor vuelve por sus fueros aunque sea bajo un disfraz esotérico. 


\section{Bibliografía}

Bachelard Gaston, El aire y los sueños, México, Fondo de Cultura Económica, 1958.

Caballero López José Antonio, «Escenas trágicas en el teatro griego: de la violencia a la retórica», en Violencia en escena y escenas de violencia en el Siglo de Oro, eds. Ignacio Arellano y Juan Antonio Martínez Berbel, New York, Idea, 2013, pp. 41-55.

Calderón de la Barca Pedro, Obras completas, Tomo I, ed. de Á. Valbuena Briones, Madrid, Aguilar, 1959.

Calderón de la Barca Pedro, La fiera, el rayo y la piedra, ed. de Aurora Egido, Madrid, Cátedra, 1980.

Gallego Morell Antonio, El mito de Faetón en la Literatura Española, Anejos de la Revista de Literatura, 1961, 18, Madrid, CSIC.

García Gual Carlos, «Procris y Céfalo, un mito de final trágico», en Libreto de Celos aun del aire matan, Madrid, Teatro Real, Fundación del Teatro Lírico, 2000, pp. 106-119.

Gutiérrez Carbajo Francisco, «Mitología y popularismo en Apolo y Climene», en Calderón 2000, Homenaje a Kurt Reichenberger en su 80 cumpleaños, vol. II, Kassel, Reichenberger, 2002, pp. 219-233.

Hernández Araico Susana, «Mitos, símbolismo y estructura en Apolo y Climene y El hijo del sol, Faetón», Bulletin of Hispanic Studies, 1987, I, 64, pp. 77-85.

Hernández Araico Susana, "Sensualidad musical en Calderón: La púrpura de la rosa, Apolo y Climene y Las armas de la hermosura», en Calderón 2000, Homenaje a Kurt Reichenberger en su 80 cumpleaños, vol. II, Kassel, Rrichenberger, 2002, pp. 245258.

Nygren Anders, Erôs et Ágape, Paris, Aubier, 1944.

Ovide, Les Méthamorphoses, Texte établi et traduit par Georges Lafaye, Paris, Les Belles Lettres, 1962, 3 vols.

Rozas J.M, «Dos notas sobre el mito de Faetón en el Siglo de Oro», en Boletín Cultural, 1963, I, 2, Madrid, Departamento Cultural de la Embajada Argentina en Madrid, pp. 81-92.

Rull Enrique, Estudio y edición crítica de Celos aun del aire matan de Pedro Calderón de la Barca, Madrid, UNED, 2004.

Rull Enrique, "El camino de la mina, vehículo de emociones en Calderón», Revista de Literatura, Madrid, CSIC, 2002, Tomo 64, No 128, pp. 385-411.

Valbuena Briones Á., «El tema de Apolo en tres <comedias> de Calderón», Thesaurus, Bogotá, 1981, XXXVI, número 2, pp. 230-244. 
